\title{
Effects of intertrial nonreinforcement (ITN) in instrumental escape conditioning
}

\author{
JEFFREY A. SEYBERT, G. LYNN VANDENBERG, MARK A. WILSON, \\ and IVAN C. GERARD \\ University of Missouri, Kansas City, Missouri 64110
}

\begin{abstract}
Two experiments investigated the effects of intertrial nonreinforcement (ITN) in a discrete-trials instrumental escape conditioning paradigm. In Experiment 1 an ITN group was more resistant to extinction than a continuously reinforced group but less resistant than a partially reinforced group. This ITN effect was replicated in Experiment 2. The performance of an additional control group in Experiment 2 suggests that this effect, in the present escape learning paradigm, may be due to a stimulus generalization decrement mechanism rather than to the operation of sequential variables.
\end{abstract}

The effects of intertrial goalbox placements are relatively well established. Reinforced intertrial placements (ITR), when interspersed between the nonreinforced $(N)$ and reinforced $(R)$ trials of a partial reinforcement (PRF) schedule, have been shown to reduce resistance to extinction $\left(R_{n}\right)$ as compared to that generated by the PRF schedule alone (e.g., Capaldi, Hart, \& Stanley, 1963). Nonreinforced intertrial placements (ITN), on the other hand, when interspersed between the $\mathrm{R}$ trials of a continuous reinforcement (CRF) schedule, have been shown to generate greater $R_{n}$ than that produced by the CRF schedule alone (e.g., Brown \& Logan, 1965).

The most widely accepted explanation of the effects of ITR and ITN is in terms of Capaldi's (e.g., 1967) sequential-memory theory. In the case of ITR, the placement is hypothesized to replace the memory of the preceding $\mathrm{N}$ trial (with the memory of the reinforced goalbox placement) and thus prevent the formation of the theoretical $S^{N}-R_{I}$ association (i.e., the conditioning of the memory of $\mathrm{N}$ to the instrumental reaction on the succeeding $R$ trial). This $S^{N}-R_{I}$ association is posited to be an important mechanism for the occurrence of the partial reinforcement extinction effect (PREE). Similarly, for the case of ITN, the placement is said to supply a memory of $\mathrm{N}$ which is subsequently available for conditioning on the succeeding $R$ trial, resulting in the formation of $S^{N}-R_{I}$ associations and a resultant increase in $R_{n}$.

To date, all of the information regarding the effects of intertrial goalbox placements has been collected from

A preliminary report of these findings was presented at the annual meeting of the Southwestern Psychological Association, Albuquerque, New Mexico, April 1976. I. C. Gerard is currently at the University of Nebraska, Omaha. Requests for reprints should be sent to J.A. Seybert, Department of Psychology, C. B. Annex, University of Missouri, Kansas City, Missouri 64110. procedures utilizing appetitive motivation and reinforcement. It was the purpose of the present experiments to investigate the effects of ITN in an aversive motivational paradigm, specifically, discrete-trials instrumental escape conditioning. Although sequential theory was originally derived from and applied to data from appetitive motivational situations, there is recent evidence (Seybert, Mellgren, Jobe, \& Eckert, 1974; Seybert, Rigby, \& Mellgren, 1976) to indicate that it can be applied to data from escape learning procedures as well. The present findings should provide information concerning this issue.

\section{EXPERIMENT 1}

Experiment 1 was designed to examine the effects of ITN in instrumental escape learning. To this end, three groups were employed: a CRF group, which received $\mathbf{R}$ trials throughout acquisition training; a PRF group, which received a combination of $\mathrm{N}$ and $\mathrm{R}$ trials during acquisition; and an ITN group, which received $\mathrm{CRF}$ on running trials interspersed with $\mathrm{N}$ placements throughout training.

It should be noted that the procedures for $\mathrm{R}$ and $\mathrm{N}$ goal events in the present experiments were designed to be as closely analogous as possible to those employed in appetitive instrumental conditioning. Specifically, an $\mathbf{R}$ escape trial consisted of the presentation of shock in the start and run sections of the alley and its absence in the goal section. An $\mathrm{N}$ escape trial was similar to an $R$ trial, except that the start-run shock level was maintained in the goalbox. A more complete description of, and justification for, this procedure may be found elsewhere (Seybert et al., 1974, 1976).

\footnotetext{
Method

Subjects. The subjects were 30 male albino rats of the Sprague-Dawley strain purchased from the Holtzman Company. At the start of training they were approximately 130 days old. Throughout the experiment the rats were individually housed
} 
and maintained on ad-lib food and water. They were randomly assigned to one of three groups ( $\mathrm{N}=10$ /group).

Apparatus. The apparatus consisted of a clear Plexiglas straight runway alley manufactured by the Hunter Company. The runway was $150 \times 15 \times 9 \mathrm{~cm}$ wide, had a grid floor throughout, and was divided into a $30-\mathrm{cm}$ start section, a $90-\mathrm{cm}$ run section, and a $30-\mathrm{cm}$ goal section. Guillotine doors separated all sections. Response latencies in the alley sections were measured by three .01-sec Standard timers. A microswitch at the startbox door activated the start timer, which was stopped by a photocell located $11 \mathrm{~cm}$ into the alley section. This photocell also started the run clock, which was stopped by a second photocell, located $11 \mathrm{~cm}$ in front of the goalbox. The goal clock was started by the second photocell and stopped by a third photocell located $9 \mathrm{~cm}$ inside the goal section. Start, run, and goal latencies were converted to reciprocals (speeds). The sum of the start, run, and goal times was converted to a reciprocal which served as a total speed measure. To minimize any effects of odor cues, the alley was thoroughly wiped following each trial in both acquisition and extinction.

A Model 700 Grason-Stadler shock generator delivered shock automatically to all sections of the alley. The shock was activated by a microswitch at the start section door. Shock delivery in the goalbox was controlled by a switch located in the apparatus control panel. Duration of shock and confinement time in the goalbox were regulated by a similarly mounted timer.

Procedure. Prior to the start of the training procedure, each subject received one $R$ pretraining trial in the apparatus. During the experiment a running trial was conducted as follows: The subject was placed in the start section for $5 \mathrm{sec}$ before the startbox door was raised. Raising the startbox door activated the first timer and the shock generator, which delivered a .6-mA shock to all sections of the runway. When the subject entered the goalbox, the goalbox door was closed. On $\mathrm{N}$ trials the $.6-\mathrm{mA}$ shock remained on in the goalbox for $30 \mathrm{sec}$. On $\mathrm{R}$ trials no shock was present in the goalbox. On $\mathrm{N}$ placements the subjects were placed in the goalbox for a 30-sec confinement period, with the shocker activated as on $\mathrm{N}$ trials.

The three groups were designated CRF, PRF, and ITN. The PRF group received the following daily reinforcement schedules on the 6 days of acquisition: RNRNR, RNRRR, RRRNR, RNRNR, RRNRR, and RNRNR, respectively. The ITN group received the following schedule of ITN (n) and running trials on the 6 days of acquisition: $R R n R R n R, R R n R R R$, RRRRnR, RRnRRnR, RRRnRR, RRnRRnR. The CRF group received five $R$ trials on each of the 6 days of acquisition training. Thus, each group received 30 acquisition training trials. Following acquisition, each subject received five extinction trials per day for 2 days. The procedure for extinction trials was identical to that on $\mathrm{N}$ trials during acquisition. No intertrial placements were administered during extinction. During both acquisition and extinction, the subjects were run in squads of six, two from each group in a squad. The ITI was 5-6 min throughout the experiment.

\section{Results and Discussion}

Similar results were obtained from all three alley sections, as well as from the total speed measure and, thus, only the total speed data are reported and discussed for both Experiments 1 and 2 .

The data from the last day of acquisition were combined into a single block for purposes of analysis. The terminal running speeds for the ITN, CRF, and PRF groups were $.61 \mathrm{~m} / \mathrm{sec}, .72 \mathrm{~m} / \mathrm{sec}$, and $.76 \mathrm{~m} / \mathrm{sec}$, respectively. The results of a one-way analysis of variance indicated a marginally significant group effect $[F(2,27)=$ $2.64, .05<\mathrm{p}<.10$ ]. Subsequent analysis using planned comparisons indicated a significant difference between Group ITN and Group PRF $[\mathrm{t}(18)=2.01$, $\mathrm{p}<.05$ ] [all comparisons reported for both of the present experiments were planned comparisons ( $t$ test) with a .05 level of significance]. Thus, the presence of ITN seems to have retarded acquisition performance, at least relative to that evidenced by the PRF group.

So that the extinction results would not be contaminated by the terminal acquisition differences, the data from the 2 days of extinction (in blocks of two trials) were transformed to a rate measure (Anderson, 1963). These data are presented in Figure 1. As can be seen in the figure, it appears that on Day 1 of extinction Groups PRF and ITN were not different from each other and were slightly more resistant to extinction than was Group CRF. On Day 2 of extinction, the groups were ordered PRF $>$ ITN $>$ CRF and the differences appear to be much larger than on Day 1. Results of 3 (groups) by 4 (trial blocks) analyses of variance on each day generally confirm these observations. On Day 1 , neither the groups main effect $[\mathrm{F}(2,27)=1.05$, $\mathrm{p}>.10]$ nor the Groups by Trial Blocks interaction $(F<1)$ reached an acceptable level of significance, although the trial blocks main effect was significant $[F(3,81)=25.02, p<.001]$. On Day 2, however, the groups main effect was significant $[F(2,27)=4.22$, $\mathrm{p}<.05]$. From the figure it appears that Group PRF was more resistant than Group ITN on the later trial blocks, while Group ITN was more resistant than Group CRF on the earlier trial blocks. The planned comparisons verify this observation; for example, PRF and ITN were significantly different on the third trial block $[t(18)=1.80]$, while the difference between ITN and CRF was significant on the second trial block $[t(18)=2.18]$. As on Day 1, the trial blocks main effect for Day 2 was significant $[F(3,81)=20.18, p<.001]$, and the Groups by Trial Blocks interaction failed to reach an acceptable level of significance $(F<1)$.

The results of the present experiment thus indicate

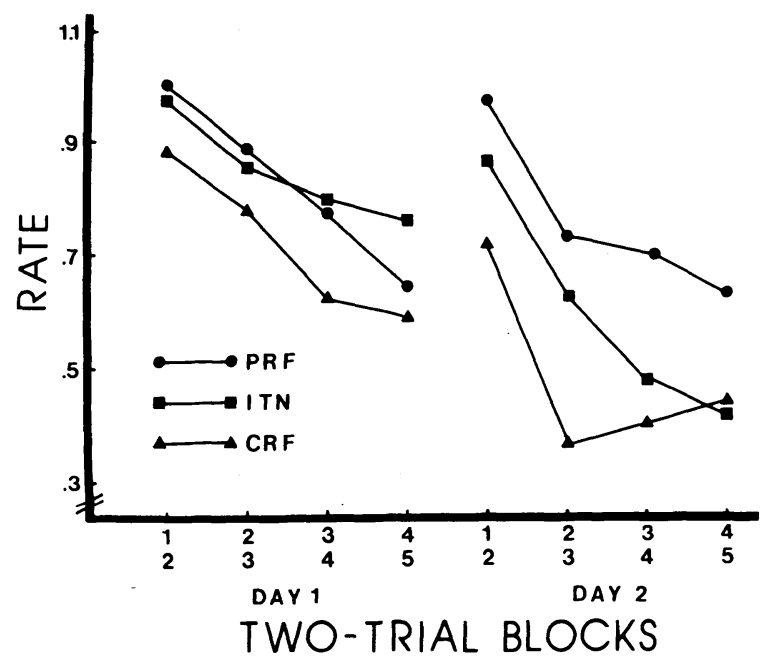

Figure 1. Mean extinction rates in two-trial blocks for the PRF, ITN, and CRF groups (Experiment 1). 
that ITN interspersed between trials of a CRF schedule increases $R_{n}$, relative to that generated by CRF alone, in a discrete-trials instrumental escape learning situation. It seems reasonable to conclude, then, that ITN operates, functionally at least, similarly in both escape and appetitively motivated learning paradigms. The question remains, however, as to the mechanism which underlies the operation of ITN in escape conditioning. Experiment 2 attempted to provide information regarding this question.

\section{EXPERIMENT 2}

As noted previously, the most probable explanation of ITN effects in appetitive situations is in terms of Capaldi's (1967) sequential-memory hypothesis. The memory of $\mathrm{N}$ from the placement replaces the $\mathrm{R}$ memory from the preceding running trial, and thus $S^{N}-R_{I}$ associations are formed, with the result being an increase in $\mathbf{R}_{\mathbf{n}}$. It is highly possible that a similar mechanism operated to produce the differences in $R_{n}$ observed between the ITN and CRF groups in Experiment 1. There is, however, a possible alternative explanation. Namely, the ITN group in Experiment 1 experienced nonreinforcement during acquisition (on the placements), whereas the CRF group did not. The observed differences in extinction (which consists of continuous nonreinforcement) between these two groups may have been simply due to differences in exposure to nonreinforcement during acquisition (i.e., a greater stimulus generalization decrement for Group CRF than for Group ITN) rather than to the conditioning of $S^{N}$ to the instrumental response. Experiment 2 attempted to test these two explanations by employing the ITN and CRF conditions as in Experiment 1, with the addition of an ITN group (Group ITN-OL) that received the $\mathrm{N}$ placements "off-line" in an apparatus completely different from the alley used in acquisition and extinction. Ostensibly, this group would have experience with nonreinforcement similar to that of Group ITN. However, since the $\mathrm{N}$ placements occur for Group ITN-OL after the daily running trials have been completed, no effective conditioning of $S^{N}$ to $R_{I}$ should take place.

\section{Method}

Subjects. The subjects were 24 rats exactly like those used in Experiment 1. They were randomly assigned to one of three groups prior to the start of the experiment ( $N=8$ /group).

Apparatus. Experiment 2 employed the same apparatus as that used in Experiment 1, with the addition of a separate shock cubicle. The gray wooden cubicle was $33 \times 23 \times 26 \mathrm{~cm}$ high, had a grid floor, and a hinged Plexiglas top. A Model 113-33 Lehigh Valley shock generator delivered shock through the grid floor of the cubicle. Onset and termination of shock were controlled by a manual switch on the shock generator. The shocker was set to deliver the same level of shock as that the subjects received in the alley.

Procedure. The procedure was identical to that employed in Experiment 1, with the exception that the ITN-OL group was added and the PRF group deleted. The CRF group received five $R$ trials on each of the 6 days of acquisition training. The ITN group received the same six daily reinforcement schedules as did the corresponding group in Experiment 1. The ITN-OL group received the following 6-day reinforcement schedule sequence: Day 1-RRRRRn*n*, Day 2-RRRRRn*, Day 3RRRRRn*, Day 4-RRRRRn*n*, Day 5-RRRRRn*, Day 6RRRRRn* $n^{*}$ ( $n^{*}=$ an "off-line" nonreinforced placement). The squad assignments, ITI in acquisition and extinction, and extinction procedure were identical to those in Experiment 1, except that only 1 day of extinction was given in Experiment 2.

\section{Results and Discussion}

As in Experiment 1, the data from the last day of acquisition were combined into a single block for purposes of analysis. The terminal acquisition running speeds for the ITN, CRF, and ITN-OL groups were $.60, .67$, and $.85 \mathrm{~m} / \mathrm{sec}$, respectively. The results of the one-way analysis of variance performed on these data indicated a significant groups effect $[\mathrm{F}(2,21)=9.14$, $\mathrm{p}<.005]$. Subsequent planned comparisons indicated that the ITN-OL group was responding faster than either the CRF or the ITN group $[\operatorname{ts}(14)=2.93$ and 4.59 , respectively]. Thus, ITN again suppressed acquisition performance, as in Experiment 1. The reason for the lack of differences between the ITN and CRF groups is unclear.

The extinction data from Experiment 2, like those of Experiment 1, were combined in two-trial blocks and transformed to a rate measure (Anderson, 1963) to obviate contamination by terminal acquisition differences. These data are seen in Figure 2. As is apparent in the figure, there were no differences in $R_{n}$ between Groups ITN and ITN-OL, and both of these groups were markedly more resistant than was Group CRF. These impressions were confirmed by the 3 (groups) by 4 (trial blocks) analysis of variance conducted on the data. The analysis revealed significant main effects for

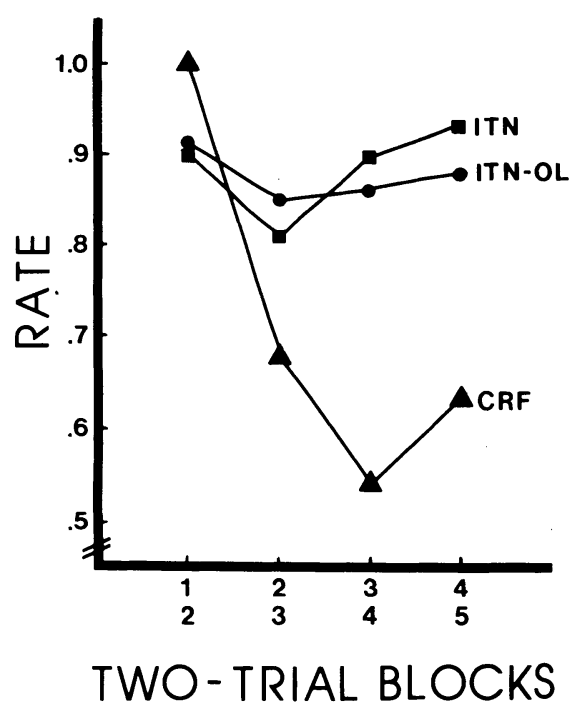

Figure 2. Mean extinction rates in two-trial blocks for the ITN, ITN-OL, and CRF groups (Experiment 2). 
groups $[\mathrm{F}(2,21)=4.11, \mathrm{p}<.05]$ and trial blocks $[F(3,63)=5.62, \mathrm{p}<.005]$, as well as a significant Groups by Triál Blocks interaction $[F(6,63)=3.95$, $\mathrm{p}<.005]$. Subsequent planned comparisons indicated that both Group ITN and Group ITN-OL were more resistant to extinction than was Group CRF $[\operatorname{ts}(14)=$ 2.25 and 2.66, respectively].

Thus, the results of Experiment 2 replicate the ITN extinction effect in the escape learning paradigm which was observed in Experiment 1. However, a concomitant increase in $\mathbf{R}_{\mathbf{n}}$ was also observed in the ITN-OL group, in which the formation of effective $S^{N}-R_{I}$ associations was ostensibly prevented. This latter finding would seem to suggest that the mechanism responsible for the ITN effect in escape conditioning is a simple generalization decrement process rather than being sequential in nature. Further, this conclusion is in disagreement with previously reported findings (Seybert et al., 1974, 1976) which have indicated that a similar sequential-memory mechanism underlies acquisition and extinction performance in both appetitively and aversively motivated instrumental learning situations. We believe, however, that extreme caution must be exercised before either of these conclusions can be seriously considered, for several reasons. First, it is possible that $S^{N} \cdot R_{I}$ associations occurred, over the 24-h ITI between days of acquisition training in the ITN-OL group. This possibility is unlikely, however, since the acquisition trials and off-line $\mathbf{N}$ placements occurred in apparatus of different shape, size, color, and construction material. That any significant increased persistence could have accrued for the ITN-OL subjects in the relatively massed trial extinction procedure employed here from $S^{N} \cdot R_{I}$ associations conditioned at a widely spaced ITI (approximately $24 \mathrm{~h}$ ) is questionable in any case. Second, escape conditioning studies which have indicated a common mechanism for appetitively and aversively motivated instrumental learning phenomena (Seybert, et al., 1974,1976 ) have, for the most part, employed a reduced shock level in the goalbox as reinforcement, rather than a complete absence of shock as in the present experiments. The importance of this procedural variation has been discussed elsewhere (Seybert et al.,
1974) and may have influenced the present results. Third, using an appetitive ITR off-line technique, conceptually similar to the present procedure, Capaldi and Spivey (1963) observed no attenuation of the PREE in their off-line ITR groups, that is, the off-line ITRs were not effective in replacing the $S^{N}$ from the running trials. Given the reasonable possibility that a common mechanism is responsible for the effects of placements regardless of motivational condition or type of placement, the discrepancy between the results of Experiment 2 here and those reported by Capaldi and Spivey (1963) may warrant further examination. Finally, the present findings also indicate that a more thorough investigation and delineation of the specific mechanism responsible for ITN effects under conditions of appetitive motivation might be warranted.

\section{REFERENCES}

Anderson, N. G. Comparison of different populations: Resistance to extinction and transfer. Psychological Review, 1963, 70, 162-179.

Brown, R. T.. \& Logan, F. A. Generalized partial reinforcement effect. Journal of Comparative and Physiological Psychology, 1965, 60, 64-69.

CAPALDI. E. J. A sequential hypothesis of instrumental learning. In K. W. Spence \& J. T. Spence (Eds.), The psychology of learning and motivation: Advances in research and theory (Vol. 1). New York: Academic Press, 1967.

Capaldi, E. J., Hart, D., \& Stanley, L. R. Effect of intertrial reinforcement on the aftereffect of nonreinforcement and resistance to extinction. Journal of Experimental Psychology, 1963, 65, 70-74.

Capaldi, E. J., \& SpIVey, J. E. Effect of goal-box similarity on the aftereffect of nonreinforcement and resistance to extinction. Journal of Experimental Psychology, 1963, 66. 461-465.

Seybert, J. A., Mellgren, R. L., Jobe, J. B., \& Eckert, E. Sequential effects in discrete trials instrumental escape conditioning. Journal of Experimental Psychology, 1974, $102,473-483$.

Seybert, J. A., Rigby, R. L., \& Mellgren, R. L. Spaced trial instrumental escape conditioning: Effects of magnitude and schedule of reinforcement. Animal Learning \& Behavior, 1976, 4, 322-328.

(Received for publication February 24, 1977.) 